\title{
Endoscopy anesthesia, team perspective
}

\author{
Daniel Muñoz-Fuentes ${ }^{1}$, José A. Cabello-Montes ${ }^{2}$, Miguel A. Herrera-Servin ${ }^{1}$, and Julio C. Zavala-Castillo ${ }^{1}$ \\ ${ }^{1}$ Service of Gastrointestinal Endoscopy; ${ }^{2}$ Service of Anesthesiology. Hospital General de México "Dr. Eduardo Liceaga," Mexico City, Mexico
}

\begin{abstract}
Sedation, at the endoscopy room, is a very important step of the procedure. It helps to perform complex therapeutical procedures with better results for patients and helps reduce related adverse effects. A specific team of doctors, such as endoscopists-anesthesiologists, has allowed to perform more and complex advanced therapeutic procedures. However, in most endoscopy centers, anesthesiologists in training (residents) are often not familiarized with sedation in endoscopic procedures that allow the passage of the equipment through the cricopharyngeal muscle, without also causing respiratory depression, and the limitation that they do not have absolute control of the airways. Various drugs are used for endoscopic procedures. However, the patient's comorbidities must be known, as well as close communication with the endoscopist doctor by the anesthesiologist to use the appropriate drug according to the endoscopic procedure. When anesthesia is not possible in patients, the endoscopist doctor must know techniques to perform high-demand procedures in high-volume centers such as upper endoscopy and colonoscopy with favorable results for the diagnosis and timely treatment of patients.
\end{abstract}

Key words: Anesthesia. Endoscopy. Sedation.

\section{Introduction}

Gastrointestinal endoscopy has changed constantly, from the beginning by Kussmaul in 1868 who performed the first gastroscopy. Today, the advance of endoscopes from fiber to high definition with magnification has made it possible to search for almost cellular changes in patients for conditions that will develop into gastrointestinal tumors, affecting the natural history of cancer ${ }^{1}$.

Advances in equipment and accessories are allowing for less invasive, curative, and palliative therapeutic procedures, thank to the joint work of anesthesiology-endoscopy, which has allowed for more complex and time-consuming procedures in advanced diseases. These conditions have led to the recognition of the need and value of the support of the anesthesiology service ${ }^{2}$.
The unique conditions of endoscopic procedures make it almost a subspecialty within anesthesiology. At present, in most hospitals, there is little or no rotation in the endoscopy service for residents during their academic training.

Anesthesiologists are used to having absolute control of the airway and are trained to adequately resolve any respiratory complications. They are used to perform anesthetic inductions in procedures where general anesthesia is required. However, in the area of endoscopy, they must find a balance between deep enough sedation to tolerate the passage of the endoscope and therapeutic maneuvers and avoid causing apnea and desaturation, with the consequent removal of the endoscope to ventilate the patient and resolve the complication.

\section{Correspondence:}

*Daniel Muñoz-Fuentes E-mail: danielmfmd@gmail.com
Available online: 29-07-2021 Rev Med Hosp Gen Mex. 2021;84(3):116-122 www.hospitalgeneral.mx 0185-1063/C 2021 Sociedad Médica del Hospital General de Mexico. Published by Permanyer. This is an open access article under the CC BY-NC-ND license (http://creativecommons.org/licenses/by-nc-nd/4.0/). 
The aim of this review is to raise awareness of the need for anesthesia and endoscopy teamwork to perform increasingly complex studies, as well as of the alternatives in case of high-volume centers to perform high-demand procedures without sedation.

In endoscopy departments, patients are assessed by both the endoscopist doctor and the anesthesiologist on the day of the procedure ${ }^{3}$. It is important to detect comorbidities (the most important of which are cardiac and respiratory conditions, overweight or obesity, craniofacial anomalies, and cancer) which help to foresee potential complications and thus determine the type of anesthetic procedure required ${ }^{4}$.

\section{Anesthetic protocol in the endoscopy area}

Part of the indications given to the patient for an endoscopic study is fasting; the American Society of Anesthesiologists (ASA) recommendations are $2 \mathrm{~h}$ for clear liquids, $4 \mathrm{~h}$ for light meals, and $8 \mathrm{~h}$ for large meals ${ }^{5}$. In the case of colonic preparation, regardless of the schedule, there is little or no gastric residue if the fasting times are respected ${ }^{6}$.

The indication for the study is of utmost importance as the presence of tumors, stenosis, or hemorrhage increases the risk of bronchoaspiration. In these cases, it is advisable to use local anesthesia or minimal sedation, keep the patient semi-sitting, and perform a quick initial check to see the gastric or esophageal contents and aspirate as much as possible to determine whether to continue with sedation or require general anesthesia to protect the airway.

Minimal monitoring in patients requiring sedation includes non-invasive blood pressure, pulse oximetry, 3-lead electrocardiogram, and in case of $\mathrm{CO} 2$ insufflation, capnograph?

\section{Sedation options}

Most patients presenting for routine endoscopy are healthy and have few comorbidities. Some will tolerate the procedure with local anesthesia alone, but most require light sedation, with an opioid and a benzodiazepine. The benefits of this sedation, especially in upper endoscopy, are amnesia, comfort, and prevention of nausea, choking sensation, and arching, conferring greater safety in the performance of the endoscopic procedure ${ }^{8}$.

The depth of sedation depends on the type of procedure to be performed and the timing of the procedure. There are situations in which the stimulus is more intense, especially if therapeutic procedures are performed (dilatation, endoscopic loops, and technical difficulties), the medication adjustments must be made quickly and carefully to avoid deepening the sedation too much, resulting in respiratory depression and desaturation, leading to interruption of the procedure to rescue the patient.

It is important to note that sedation is a continuum ${ }^{9}$, each patient responds differently to medications and may progress to a deeper level of sedation than planned and even to the general anesthesia phase at the usual doses. The challenge is even greater because the presence of comorbidities, previous medications, age, and history of substance abuse, all play a role in the response to anesthetic drugs ${ }^{10}$. More advanced endoscopic procedures are performed under deep sedation or general anesthesia to avoid interruptions of the procedure due to respiratory disturbance, allowing for shorter procedure times and fewer adverse effects.

Drugs used in anesthetic procedures in endoscopy should share some essential characteristics: rapid onset of action, rapid termination of effect, easy dose adjustment, no cardiovascular disturbances, and no increased risk of post-operative nausea and vomiting.

The drugs are used in combination, the most common being midazolam/fentanyl/propofol. When combined, the initial and total doses of each are significantly decreased, the doses described below (Table 1) are those used in this scenario.

Some considerations and characteristics in the use of these drugs are described below:

\section{Midazolam}

Not recommended for use in patients over 6065 years of age due to an increased incidence of neurological adverse effects (delirium), and some studies have shown that the incidence of hiccups during studies increases when using more than $2 \mathrm{mg}^{11}$. Not recommended for use in patients with liver or kidney failure.

\section{Fentanyl}

Over dosage causes apnea and the need for rescue ventilation.

\section{Propofol}

The most common drug for deep sedation or general anesthesia. It has dose-dependent hypotensive properties 
Table 1. Commonly used drugs in sedation for endoscopic procedures

\begin{tabular}{|c|c|c|c|c|c|}
\hline Drug & Type & Dose & $\begin{array}{l}\text { Initial } \\
\text { effect }\end{array}$ & $\begin{array}{l}\text { Duration of } \\
\text { effect }\end{array}$ & Remarks \\
\hline Midazolam & $\begin{array}{l}\text { Anxiolytic } \\
\text { Benzodiazepine }\end{array}$ & $\begin{array}{l}\text { Initial } 0.5-2 \mathrm{mg} \text { (bolus), } \\
0.5-1 \mathrm{mg} \text { (repeat in boluses every } 2 \mathrm{~min} \text { ) }\end{array}$ & $2-5 \min$ & $15.8 \mathrm{~min}$ & $\begin{array}{l}\text { Complete removal in } \\
6 \mathrm{~h}\end{array}$ \\
\hline Fentanyl & $\begin{array}{l}\text { Analgesic } \\
\text { Opioid }\end{array}$ & $\begin{array}{l}\text { Initial } 2 \mathrm{mcg} / \mathrm{kg} \\
1-1-5 \mathrm{mcg} / \mathrm{kg} \text { (obese) } \\
0.5 \mathrm{mcg} / \mathrm{kg} \text { (repeat in boluses every } 2 \mathrm{~min} \text { ) }\end{array}$ & $2-5 \min$ & $45-60 \mathrm{~min}$ & -- \\
\hline Sufentanil & $\begin{array}{l}\text { Analgesic } \\
\text { Opioid }\end{array}$ & $\begin{array}{l}\text { Initial } 0.1-0.2 \mathrm{mcg} / \mathrm{kg} \\
0.05 \mathrm{mcg} / \mathrm{kg} \text { (boluses every } 3-4 \mathrm{~min} \text { ) }\end{array}$ & $4-6 \min$ & $40-50 \min$ & $\begin{array}{l}10 \text { times more potent } \\
\text { than fentanyl }\end{array}$ \\
\hline Remifentanil & $\begin{array}{l}\text { Analgesic } \\
\text { Opioid }\end{array}$ & $\begin{array}{l}\text { Continuous infusion } 0.04 \text { - } \\
0-16 \mathrm{mcg} / \mathrm{kg} / \mathrm{min}\end{array}$ & $<90 \mathrm{sec}$ & $6-10 \mathrm{~min}$ & $\begin{array}{l}\text { Opioid ideal for use in } \\
\text { endoscopy }\end{array}$ \\
\hline Propofol & $\begin{array}{l}\text { Hypnotic } \\
\text { GABA agonist }\end{array}$ & $\begin{array}{l}\text { Boluses: initial } 0.3-0.4 \mathrm{mg} / \mathrm{kg} \text {, supplement } \\
\text { with } 0.1-0.2 \mathrm{mg} / \mathrm{kg} \text { every } 40-60 \mathrm{sec} \text {. } \\
\text { At study initiation, boluses } 0 \\
0.2-0.3 \mathrm{mg} / \mathrm{kg} \text { every } 2-3 \mathrm{~min} \\
\text { Infusion: } 60-150 \mathrm{mcg} / \mathrm{kg} / \mathrm{min} \\
\text { adjusting dose }\end{array}$ & $30-45 \mathrm{sec}$ & 4-8 $\min$ & $\begin{array}{l}\text { Most commonly used } \\
\text { agent in endoscopy }\end{array}$ \\
\hline Ketamine & NMDA agonist & $0.3-0.5 \mathrm{mg} / \mathrm{kg}$ in adults & --- & --- & $\begin{array}{l}\text { Facilitates the passage } \\
\text { through the } \\
\text { cricopharyngeal muscle }\end{array}$ \\
\hline Dexmedetomidine & $\begin{array}{l}\text { Alpha } 2 \text { agonist } \\
\text { Hypnotic }\end{array}$ & $0.2-0.5 \mathrm{mcg} / \mathrm{kg}, 10 \mathrm{~min}$ bolus & --- & --- & $\begin{array}{l}\text { Respiratory } \\
\text { depression is much } \\
\text { less than with the } \\
\text { other medicines }\end{array}$ \\
\hline
\end{tabular}

kg: kilogram; mcg: microgram; mg: milligram; min: minute; sec: second.

and causes respiratory depression. Benefits include antiemetic and antipruritic properties, interferes with swallowing and functional integrity of the upper airway. Synergizes with opioids and benzodiazepines for respiratory adverse effects. Dosage is lower in elderly, hypovolemic patients and in the presence of comorbidities.

\section{Ketamine}

It produces dissociative anesthesia. It can be used as a single anesthetic, but adverse effects (hallucinations) limit it to use mainly in the pediatric population. Among its undesirable effects are drooling, which can make airway management difficult, so it is necessary to administer antisialogogues (atropine, 0.3-0.5 mg, or glycopyrrolate) to avoid it ${ }^{12}$.

\section{Dexmedetomidine}

It can produce bradycardia and hypotension as side effects, so it is beneficial in hypertensive patients or those with cardiovascular pathology. It is not widely used because residual sedation usually lasts longer, and this is a problem in outpatient procedures, delaying discharge from $30 \mathrm{~min}$ to $2 \mathrm{~h}$.
The steps to be taken for sedation in an upper endoscopic procedure are to determine whether sedation or general anesthesia will be used. If it is the first option, the patient is admitted to the room, monitored, and a device is placed to administer supplementary oxygen (nasal prongs, nasal mask, or facemask with an endoscope opening). Then, the patient is placed in the left lateral decubitus position and medication is started with fentanyl (1.5-2 $\mathrm{mcg} / \mathrm{kg}$ ) and midazolam (1-2 $\mathrm{mg} \mathrm{IV}$ ). After 3-5 min, the mouthpiece is placed, at which time topical anesthesia (lidocaine) may or may not be administered. Ketamine $(0.3 \mathrm{mg} / \mathrm{kg})$ and atropine $(0.3$ to $0.5 \mathrm{mg}$ ) are then administered, and the infusion of propofol is started. At this point, it is very important to start slowly and adjust the infusion to low doses. The incidence of apnea is very high, especially for anesthesiologists unaccustomed to out-of-theater procedures, and is not always immediate.

The most difficult moment is the passage of the endoscope through the cricopharyngeal muscle. The most common problem is that at the beginning of the endoscopy the patient does not tolerate the passage and requires additional doses of medication. If these are not adequately titrated, the patient will tolerate the passage of the endoscope, but will also stop breathing, 
and after 30-90 s will present desaturation and will require rescue ventilation and a pause in the study to remove the endoscope.

Once the cricopharyngeal muscle is surpassed, the movements of the endoscope do not cause as much discomfort and generally do not require sudden adjustments of the medication, except at specific times (cutting, dilatation, and balloon use). It is of utmost importance to avoid overdosing if the patient is moving, as stress and the need to stop movement at these times may cause the dose to be excessive and lead to a respiratory emergency.

Communication with the endoscopy team as well as knowledge of the procedure to be performed is necessary to anticipate painful events (balloon inflation, passage of the endoscope through difficult areas, and excessive distension) and adjust the dosage accordingly.

In the case of lower endoscopy (colonoscopy), it has been observed that with shallower levels of sedation, the incidence of perforations decreases (by warning that excessive pressure is being applied and therefore stopping it in time $)^{13}$.

In general, depending on the duration of the procedure, fentanyl boluses are repeated every 20-40 min, analgesics and/or antispasmodics may be added. Finally, once the procedure is completed, the infusion is stopped, secretions are aspirated and the patient is monitored until alertness is restored.

\section{Airway adjuvants}

During deeper phases of sedation, instruments are needed to provide adequate oxygen flow and airway protection, as even if spontaneous breathing is maintained, ventilation may be inadequate, especially in upper endoscopy.

Maneuvers such as jaw traction, cervical extension, use of continuous positive airway pressure nasal masks, face masks with endoscope port, high-flow nasal prongs, and in some cases, either primary or rescue, airway sharing devices such as gastrolaryngeal tubes, and laryngeal mask airway Gastro ${ }^{\mathrm{TM}}$ mask are necessary ${ }^{14}$. Patient characteristics will determine the type of support (Fig. 1).

Securing the airway should not be considered a failure of the anesthesiologist; intubation is the safest way to protect the airway should regurgitation occur. It may be necessary at any time, especially in long or complex procedures.

Some of the indications for intubation in endoscopy include emergency procedures, severe respiratory or

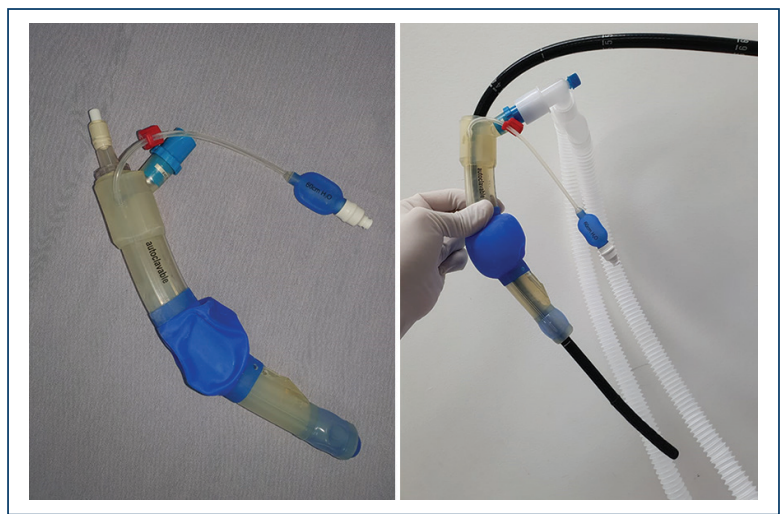

Figure 1. Laryngeal Mask (Medizintechnik GmbH) airway device with a hole for endoscope insertion and a hole for ventilation.

cardiac comorbidities, morbid obesity, bowel obstruction, anatomical problems, duration of procedures (arbitrarily more than $60 \mathrm{~min}$ ), complexity of the procedure, and drainage of pancreatic pseudocysts, use of double balloon, and use of large amounts of irrigation fluid, among the most important. The use of $\mathrm{CO}_{2}$ for distention requires monitoring of exhaled $\mathrm{CO}_{2}$ due to the large amount of absorption. Air embolism can occur, mainly during sphincterotomy and mucosectomy (Fig. 2).

\section{Endoscopic scenario}

\section{Esophagogastroduodenoscopy (EGD)}

EGD or upper endoscopy is a diagnostic and therapeutic tool that allows screening for different gastrointestinal neoplasms and treatment of different diseases, whether elective or emergency.

In general, endoscopic studies are performed with the aid of sedation by the anesthesiology service, however, in some high-volume centers; the study is only performed with topical anesthesia to suppress the gag reflex during the procedure. The most commonly used agents are lidocaine, benzocaine, and tetracaine, administered as an aerosol into the pharynx. Lidocaine, with an average dose of $60 \mathrm{mg}$ (range 40-80 mg), can be administered by the endoscopist doctor or nurse, improving ease of endoscopy and patient tolerance ${ }^{15}$. Topical anesthetics have been associated with serious adverse effects such as aspiration, anaphylaxis, or methemoglobinemia. Therefore, they should be used with caution (Fig. 3).

In most patients who undergo an endoscopic study without sedation, the most common post-procedural side effects are odynophagia, abdominal distension, 


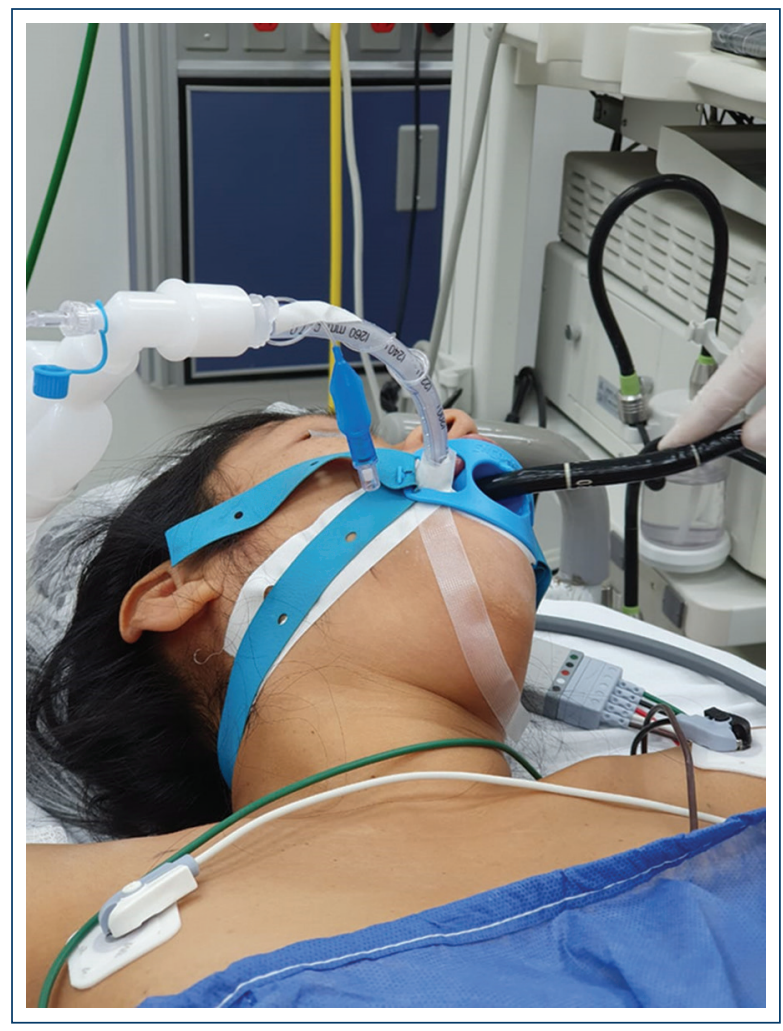

Figure 2. General anesthesia in balloon-assisted enteroscopy, the best option in complex procedures.

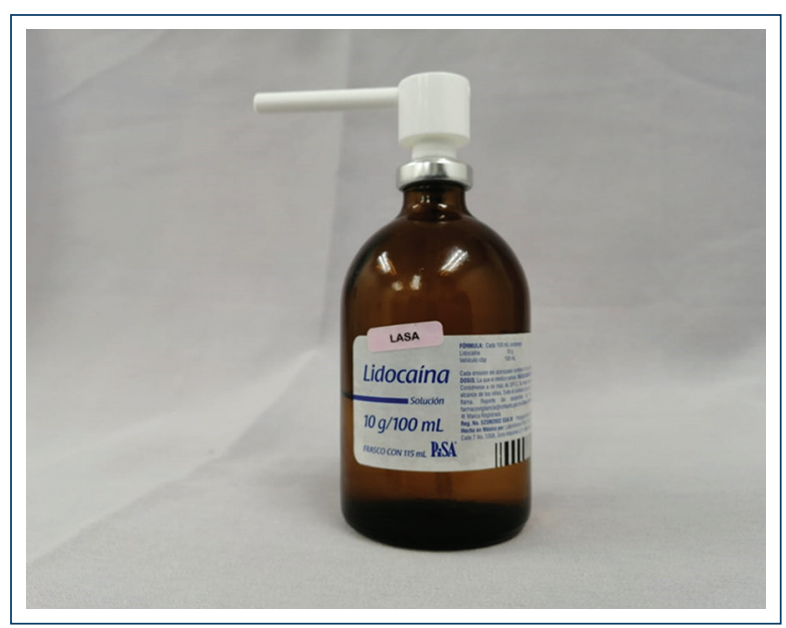

Figure 3. Lidocaine solution.

and colicky pain. These side effects in some patients make the study dreaded at subsequent endoscopic follow-up appointments, or even poorly recommended to their family and friends. The latter may result in a loss of follow-up in patients and thus increased risk of morbidity in them.
In addition, the endoscopist doctor who performs a procedure under local anesthesia knows that it is a quicker and in most cases, more targeted study, and in some cases, lesions may go unnoticed compared to a sedated study where a more thorough inspection can be performed.

Sedation in panendoscopy has several advantages, including causing amnesia of the procedure, which helps to forget the event and prevent anxiety about it, allowing subsequent studies to be performed. Moreover, in case of therapeutic procedures, these can be performed without haste and incomplete procedures can be avoided.

The adverse effects of sedation include respiratory depression, hypoxia, cardiovascular changes, and allergies, among others. Therefore, the anesthetic technique to be used on patients should be selected according to the urgency of the procedure and comorbidities ${ }^{16}$.

\section{Colonoscopy}

Colonoscopy has become a screening method of choice for colorectal cancer, as well as for the diagnosis and treatment of colonic diseases. It requires bowel preparation and sedation to perform a painless study, with less technical difficulty, and to reduce the patient's anxiety for subsequent follow-up studies.

Due to the aforementioned adverse effects of sedation, strategies have been tried to perform the study without anesthesia, keeping the patient pain free, and obtaining the same results in terms of study quality criteria according to the ASGE guidelines (cecal intubation and adenoma detection rate) ${ }^{17}$.

In 2018, Bashiri et al. in a Turkish study used music therapy as a strategy to reduce the dose of anesthetics, anxiety, and pain in patients who underwent colonoscopy with conscious and deep sedation. They observed that patients who underwent the procedure with music used lower doses of drugs, had less pain and anxiety after the procedure, compared with those who underwent the study without music ${ }^{18}$. This undoubtedly generates strategies to balance the benefits and risks of the use of sedation in this procedure, however, randomized clinical studies are required in our environment comparing this strategy with the conventional sedation developed in this review.

It may be difficult for a patient to desire a colonoscopy study without sedation, in some cases, its administration shows more risk than benefit, so the endoscopist doctor must seek strategies to perform the procedure with the least risk and most benefit. 
Colonoscopy under water immersion is a strategy for performing the study, described since the 1980s, water helps to elongate the sigmoid, reduces the formation of loops, and does not generate distension, which helps to reduce the pain of colonoscopy, and requires minimal or no sedation ${ }^{19,20}$. Changes in position (turning the patient) during colonoscopy help to open up the angles of the colon and is a strategy to reduce pain during the study ${ }^{21}$.

\section{Post-procedural complications}

The incidence of complications in anesthetic (sedation) procedures in endoscopy is very low, Behrens reported an incidence of minor complications $(0.3 \%)$, major complications $(0.01 \%)$, and death $(0.005 \%)$ among 368,206 electronic records. ASA class, type, and duration of procedure were significant factors for adverse outcomes ${ }^{22}$. In the United States, $53 \%$ of medicolegal cases closed were for adverse events associated with respiratory causes.

Reports that are more recent have found that the likelihood of adverse events was higher in patients whose care involved anesthesia personnel, and the incidence of bleeding and perforations was higher. While these findings may not indicate causality, it is more likely that the services of the anesthesia team are more sought after in patients with higher risks (sicker, more complex procedures, and older) and this is part of this higher incidence of adverse events.

Regarding the incidence of perforation and bleeding, the use of deeper planes of sedation implies a higher pain tolerance in patients, so there is not the necessary feedback in case the endoscope pressure or maneuvers cause excessive stress or damage to the gastrointestinal tract.

\section{Conclusions}

- The complexity of maintaining the patient by the anesthesiology service at an adequate level of sedation to perform the procedure means that the endoscopist doctor is increasingly requesting an experienced team as therapeutic procedures have greatly advanced.

- It is important for the anesthesiologist to have a detailed knowledge of the drugs for use in endoscopy to choose the appropriate option for the type of patient, helping to perform a successful and increasingly complex endoscopic procedure with the least risk to the patient.

- The safety of anesthesia in advanced therapeutic endoscopic procedures is undeniable, which is why you should communicate with the anesthesiology team about the procedure plan to match it with the anesthetic plan that leads to joint success in patient care.

- It is important to know different strategies to perform the procedure without sedation, in case, the patient's conditions do not allow it when their anesthetic risk is greater than the benefit of the procedure, however, the study will change the course of their disease or help in therapeutic decisions that impact on morbidity and mortality.

- This review was written to give an overview of the importance of multidisciplinary work in patient care in the area of endoscopy; the subsequent feasibility of randomized comparative studies will be assessed.

\section{Acknowledgments}

This review paper was a joint collaboration of the gastrointestinal endoscopy and anesthesia service. Because good communication and anesthetic management contribute to a successful endoscopic procedure.

\section{Conflicts of interest}

The authors declare that they have no conflicts of interest.

\section{Funding}

No financial support was received in the realization of this article.

\section{Ethical disclosures}

Protection of human and animal subjects. The authors declare that no experiments were performed on humans or animals for this study.

Confidentiality of data. The authors declare that they have followed the protocols of their work center on the publication of patient data.

Right to privacy and informed consent. The authors declare that no patient data appear in this article.

\section{References}

1. Chandrasekhara V, Elmunzer BJ, Khashab M, Muthusamy VR. Clinical Gastrointestinal Endoscopy. $3^{\text {rd }}$ ed. Amsterdam: Elsevier; 2019.

2. Nagrebetsky A, Gabriel RA, Dutton RP, Urman RD. Growth of nonoperating room anesthesia care in the United States: a contemporary trends analysis. Anesth Analg. 2017;124:1261-7.

3. Tetzlaff JE, Vargo JJ, Maurer W. Nonoperating room anesthesia for the gastrointestinal endoscopy suite. Anesthesiol Clin. 2014;32:387-94. 
4. Bhavani SS, Abdelmalak B. Nonoperating room anesthesia: anesthesia in the gastrointestinal suite. Anesthesiol Clin. 2019;37:301-16.

5. Practice guidelines for preoperative fasting and the use of pharmacologic agents to reduce the risk of pulmonary aspiration: application to healthy patients undergoing elective procedures: an updated report by the American society of anesthesiologists task force on preoperative fasting and the use of pharmacologic agents to reduce the risk of pulmonary aspiration. Anesthesiology. 2017:126:376-93.

6. Bucci C, Rotondano G, Hassan C, Rea M, Bianco MA, Cipolletta L, et al. Optimal bowel cleansing for colonoscopy: split the dose! A series of meta-analyses of controlled studies. Gastrointest Endosc. 2014:80:566-76.e2.

7. Practice guidelines for moderate procedural sedation and analgesia 2018: a report by the American society of anesthesiologists task force on moderate procedural sedation and analgesia, the American association of oral and maxillofacial surgeons, American college of radiology, American dental association, American society of dentist anesthesiologists, and society of interventional radiology. Anesthesiology. 2018;128:437-79.

8. Early DS, Lightdale JR, Vargo JJ $2^{\text {nd }}$, Acosta RD, Chandrasekhara V, et al. Guidelines for sedation and anesthesia in GI endoscopy. Gastrointest Endosc. 2018;87:327-37.

9. ASA. Continuum of Depth of Sedation: Definition of General Anesthesia and Levels of Sedation/Analgesia*. Committee of Origin: Quality Management and Departmental Administration. United States: ASA; 2014 Available from: https://www.asahq.org/standards-and-guidelines/continuum-of-depth-of-sedation-definitionof-general-anesthesia-and-levels-of-sedationanalgesia.

10. Woodward ZG, Urman RD, Domino KB. Safety of non-operating room anesthesia: a closed claims update. Anesthesiol Clin. 2017:35:569-81.

11. Chien CL, Cheng YL, Chi FC. Sedation-associated hiccups in adults undergoing gastrointestinal endoscopy and colonoscopy.World J Gastroenterol. 2012;18:3595-601.

12. Elazzazi $\mathrm{H}$, Saleh AA. Comparison between different atropine doses as an antisialogogue for patients receiving ketamine-midazolam undergoing gamma-knife radiosurgery. Ains Shams J Anesthesiol. 2014;7:336-9.
13. Bielawska B, Hookey LC, Sutradhar R, Whitehead M, Xu J, Paszat LF, et al. Anesthesia assistance in outpatient colonoscopy and risk of aspiration pneumonia, bowel perforation, and splenic injury. Gastroenterology. 2018;154(1):77-85.e3.

14. Terblanche NCS, Middleton C, Choi-Lundberg DL, Skinner M. Efficacy of a new dual channel laryngeal mask airway, the LMA®Gastro' ${ }^{\mathrm{TM}}$ Airway, for upper gastrointestinal endoscopy: a prospective observational study. Br J Anaesth. 2018;120:353-60.

15. Evans LT, Saberi S, Kim HM, Elta GH, Schoenfeld P. Pharyngeal anesthesia during sedated EGDs: is "the spray" beneficial? A meta-analysis and systematic review. Gastrointest Endosc. 2006;63:761-6.

16. Igea F, Casellas JA, Gonzalez-Huix F, Gómez-Oliva C, Baudet JS, Cacho G, et al. Sedation for gastrointestinal endoscopy. Endoscopy. 2014:46:720-31.

17. Paggi S, Radaelli F, Amato A, Meucci G, Spinzi G, Rondonotti E, et al. Unsedated colonoscopy: an option for some but not for all. Gastrointest Endosc. 2012;75:392-8.

18. Bashiri M, Akçalı D, Coskun D, Cindoruk M, Dikmen A, Cifdalöz BU. Evaluation of pain and patient satisfaction by music therapy in patients with endoscopy/colonoscopy. Turk J Gastroenterol. 2018;29: 574-9.

19. Iqbal N, Ramcharan S, Doughan S, Shaikh I. Colonoscopy without sedation: patient factors alone are less likely to influence its uptake. Endosc Int Open. 2016;4:E534-7.

20. Catinean A, Neag MA, Tulbure M. The advantages of water immersion colonoscopy in ambulatory service. Turk J Gastroenterol. 2019;30: 636-40.

21. Jean-Marc D, Riphaus A, Schreiber F, Vilmann $P$, Beilenhoff $U$, Aparicio JR, et al. NAAP: ESGE-ESGENA guideline 2015. Endoscopy. 2015;47:1175-89.

22. Behrens A, Kreuzmayr A, Manner H, Koop H, Lorenz A, Schaefer C et al. Acute sedation-associated complications in $\mathrm{Gl}$ endoscopy (ProSed 2 study): results from the prospective multicentre electronic registry of sedation-associated complications. Gut. 2018;68:575. 